\title{
LA REPRESIÓN DE LO IMAGINARIO EN EL CAMPO LITERARIO MEXICANO DEL SIGLO XX
}

\author{
JUAN RAMÓN VÉLEZ GARCÍA
}

Universidad de Salamanca

\begin{abstract}
This work seeks to study, within the Mexican literary field of the XXth century, the situation of some authors who have been segregated from it because of their refusal to yield their work to the requirements of nationalistic themes. I'm going to take as examples of the aforementioned ideas two illustrative cases: the authors who were members of the group Contemporaneos (such as Xavier Villaurrutia, José Gorostiza, Jorge Cuesta, Gilberto Owen, Salvador Novo...) and the writer Francisco Tario (pseudonym adopted by Francisco Peláez).
\end{abstract}

\section{Introducción}

El objetivo de este trabajo es estudiar, dentro del campo literario mexicano del siglo XX, la situación de algunos autores que han experimentado la segregación dentro del mismo al no plegar su labor a las exigencias de la temática nacionalista. Voy a tomar como ejemplos de lo mencionado dos casos ilustrativos: los autores pertenecientes al grupo Contemporáneos (donde se englobaría a Xavier Villaurrutia, José Gorostiza, Jorge Cuesta, Gilberto Owen, Salvador Novo...) y el escritor Francisco Tario (seudónimo de Francisco Peláez).

Los antecedentes del nacionalismo literario de México se remontan a la Independencia. Uno de sus principales adalides fue Ignacio Manuel Altamirano, quien abogaba por el tratamiento de temas propiamente mexicanos, basándose en "el convencimiento de que nuestras letras, artes y ciencias necesitaban nutrirse de nuestros propios temas y temperamento y de nuestra propia realidad: es decir, convertirse en nacionales, para que lograran ser expresión real de nuestro pueblo y elemento activo de nuestra integración nacional"1. El despertar del sentimiento nacionalista a partir de ese momento histórico es, como señala González Peña, "un fenómeno trascendental" y "una fuerza espiritual encaminada a dar a la producción literaria de México aún más propia,

\footnotetext{
${ }^{1}$ Citado en Alí CHUMACERO, Los momentos críticos, México; FCE, 1987, 65.
} 
inconfundible fisonomía". Desde los primeros pasos de México como nación se detecta una marcada imbricación entre la política y la labor literaria; así, durante el torbellino revolucionario de gran parte del siglo XIX acusó José Bernardo Couto una "invasión de los estudios políticos y económicos, que se llevaron poderosamente la atención de muchos, y casi ahogaron la delicada planta de la literatura"3. La Revolución Mexicana marcaría el inicio de una tendencia hegemónica durante buena parte del XX y conducente a "la creación de un canon de literatura realista y con fuerte contenido social, civilizadora, casi didáctica, casi con la obligación de mostrar un retrato de la realidad más apremiante y un camino a seguir" ${ }^{\text {"4 }}$. Domingo Miliani denuncia la gestación de "un nacionalismo exacerbado que no admite ningún género de crítica o revisión sana de los procesos", desencadenante de una "hipertrofia nacionalista" " que conllevaría "un elemento negativo de considerable gravedad: un aislamiento cultural [...] del que los nuevos artistas e intelectuales intentan sacudirse furiosamente" . Vamos ahora a detenernos en algunos de los escritores que optaron por escapar de la "ergástula literaria" en que devendría esa concepción reduccionista de la creación.

\section{Los Contemporáneos}

Pedro Ángel Palou sostiene que al grupo de Contemporáneos se debe "una labor colectiva y larga para constituir al campo literario como un espacio independiente de las pugnas económicas y políticas" que les costaría la expulsión de "la Ciudad del Nacionalismo Mexicano" sus integrantes, desencantados con el devenir socio-histórico del país "se aislaron en un mundo privado, poblado por los fantasmas del erotismo, el sueño

${ }^{2}$ Carlos GONZÁLEZ PEÑA, Historia de la literatura mexicana: desde los orígenes hasta nuestros días (con un apéndice elaborado por el Centro de Estudios Literarios de la Universidad Nacional Autónoma de México), México, Porrúa, 1984, 118.

${ }^{3}$ Citado en ibidem, 138.

4 Ana María MORALES, "El cuento fantástico en México: fin de Siglo, nuevo Siglo", en: Susanne IGLER, Thomas STAUDER (eds.), Negociando identidades, traspasando fronteras. Tendencias en la literatura y el cine mexicanos en torno al nuevo milenio, Madrid / Frankfurt, Iberoamericana / Vervuert, 2008, 215.

${ }^{5}$ Domingo MILIANI, La realidad mexicana en su novela de hoy, Caracas, Monte Ávila, 1968, 33-34.

${ }^{6}$ Ibidem 34.

${ }^{7}$ Ibidem 35-36.

8 Ibidem 49.

${ }^{9}$ Pedro Ángel PALOU, La casa del silencio. Aproximación en tres tiempos a Contemporáneos, México, El Colegio de Michoacán, 1997, 38.

${ }^{10}$ Ibidem 15. 
y la muerte. Un mundo regido por la palabra ausencia"11. Habla de un exilio interior al cual se verían abocados estos autores, en cuyas carreras literarias no habría que obviar la importancia cohesionadora de publicaciones como la que dio nombre al grupo, o El Hijo Pródigo, dirigida por Octavio G. Barreda, de cuyo primer consejo de redacción formaron parte Paz, Villaurrutia, Alí Chumacero, Celestino Gorostiza y Antonio Sánchez Barbudo. Paz dice que esta última, "sobre todo en sus primeros números, fue una revista polémica que defendió, frente a la confusión entre arte y propaganda, la libertad de la imaginación""

Los Contemporáneos, instalados así en una posición problemática, fueron reprendidos por varios diputados, funcionarios de Bellas Artes y otros escritores escritores que les reprocharon falta de compromiso político y los acusaron de ser poetas exquisitos, decadentes y cosmopolitas. Ermilo Abreu Gómez los consideró como una "capilla hermética y europeizante", y ante el requerimiento de resucitar una revista similar a Contemporáneos replicó invocando la necesidad de "una revista más de acuerdo con la realidad de México, de la tierra y de los hombres"13. Opinaba que un literato "que no tiene conciencia de la literatura a que pertenece casi no es un literato. Es un ente aislado, un extraño en su patria, un creador de mitos -de mitos infecundos, sin milagro y sin entraña" ${ }^{\prime 2}$. Estas declaraciones pueden tomarse como un ataque frontal a quienes traicionasen esa supeditación a la "mexicanidad" a ultranza preconizada por algunos detractores ${ }^{15}$.

No obstante, en 1930 el propio Villaurrutia haría profesión de fe de esa condición paratópica y reivindicaría un cierto turrieburnismo al afirmar que los poetas mexicanos "no son hombres representativos, son héroes, son la excepción y no la regla, están en contradicción con la raza de la que han surgido. Los poetas se divorcian de las masas. No son regionales [...]. Su obra no es el espejo de México"16. Jorge Cuesta, por su parte, opina que ese desgajamiento atribuido a Contemporáneos con respecto al cuerpo social constituye su paradójica afirmación de mexicanidad esencial e intrínseca: "somos nosotros, a quienes se

\footnotetext{
11 Octavio PAZ, "Xavier se escribe con equis", prólogo a: Xavier Villaurrutia (antología), México, FCE, 1980, 17.

12 Ibidem 14. El énfasis es mío.

${ }^{13}$ Citado en: Manuel DURÁN (selec.), Antología de la revista Contemporáneos, México, FCE, 1973, 20.

${ }^{14}$ Ermilo ABREU GÓMEZ, "Reflexiones literarias", en: José Luis MARTÍNEZ (selec.), El ensayo mexicano moderno (vol. I), México, FCE, 1971, pp. 419-420.

15 Otra declaración sintomática de estas posiciones es la siguiente proclamación de Victoriano Salado Álvarez en la década de los 20: "No hay literatura nueva, y la que hay no es mexicana [...] y a veces ni siquiera literatura" (citado en: Luis Mario SCHNEIDER, Ruptura y continuidad. La literatura mexicana en polémica, México, FCE, 1975, 167).

${ }^{16}$ Xavier VILLAURRUTIA, Obras. México, FCE, 1966, 618.
} 
nos llama desarraigados, los verdaderamente mexicanos, ya que no hay nada más mexicano que estar 'desarraigado', y vivir en un aislamiento intelectual' ${ }^{17}$.

Sirvan estas declaraciones cruzadas como muestras de las tensiones que han recorrido el campo literario mexicano: de un lado se exige la liberación de los tiempos marcados en el meridiano de Greenwich, contemplados como una inconveniente intrusión foránea. De otro, la liberación de un papel ancilar en relación a la política local y a las exigencias de un carácter estrictamente mimético como el solicitado expresamente por Victoriano Salado Álvarez, para quien "siendo la literatura exacta representación de la vida, no puede decirse que cumpla con su objeto más que reproduciendo aquello que acontece en el mundo"18. Al respecto son también significativos los elogios que Daniel Cosío Villegas dedicó a las novelas de Xavier Icaza, las cuales "son mexicanas. Sus personajes, el medio, las costumbres, el sabor, son del país. No es poco el mérito de este esfuerzo, ya que significa la liberación de las malas importaciones extranjeras a que estamos sujetos todavía"19. En estos espacios literarios "desheredados" la aproximación voluntaria de algunos autores a las corrientes irradiadas desde el "centro" (Europa en este caso) es vista con recelo en muchos casos.

Por su parte, Celestino Gorostiza cuestionaba este tipo de acusaciones a los Contemporáneos en su comentario a la Galería de poetas nuevos de México de Gabriel García Maroto: "Motivo de reproche ha sido para ellos, otras veces, respirar atmósferas distintas a las que se revuelven donde tienen los pies. Es el mismo reproche que haría un náufrago sin fuerzas, a otro, capaz de sostenerse a flote ${ }^{20}$. Su hermano José, probablemente el poeta más conspicuo del grupo junto con Villaurrutia, trazó un análisis del papel y estatus del escritor en la historia del país, atendiendo a los condicionantes socio-históricos influyentes en la constitución de la figura del escritor mexicano y en las opciones que ha seguido, dibujando como un erial el escenario propiciado por la lógica preponderante tras la Revolución:

La profesión del escritor no ha existido nunca entre nosotros por razones que no puedo comentar sin peligro de apartarme radicalmente de mi asunto. Tal es su complejidad. Baste pues, con decir que, a falta de las condiciones sociales en que la literatura se hace una profesión, el escritor ha subsistido hasta ahora artificialmente, como en un invernadero, al calor de la protección oficial o particular; protección que se ha ido retirando

${ }^{17}$ Jorge CUESTA, Poemas y ensayos (vol. III), México, UNAM, 1964, 376-377.

18 Victoriano SALADO ÁLVAREZ, Sobre la inmoralidad en la literatura. México, Casa de los Sucesores de Juan Pablos, 1909, 18.

${ }^{19}$ Citado en PALOU, op. cit., p. 88.

${ }^{20}$ Citado en DURÁN, op. cit., 242. 
gradualmente, aunque sin deliberación alguna, a partir de la Revolución, aun a los intelectuales que se han formado después de 1910. [...]

De la Revolución, durante su fase guerrera, no era de esperar que hiciese otra cosa que mostrarse indiferente hacia una intelectualidad adversa; después, en la fase actual y no obstante que se ha formado ya una inteligencia nueva, como quedó dicho, encontrándose el país entregado a su reconstrucción material, el escritor resulta un elemento superfluo, si no inútil, a los ojos de una colectividad laboriosa e inculta para quien escribir es una especie de gracia o don natural que se ejerce minutos antes de las veladas literarias y que no implica ninguna preparación o sacrificio. Unos no lo consideran como trabajo; otros, que escriben trabajosamente hasta su propio nombre, lo consideran como un trabajo que no puede aportar nada al bienestar social y sí, mucho, al malestar personal ${ }^{21}$.

Asimismo, realizó una prospección al problema de las reiteradas acusaciones de falta de nacionalismo en otro escrito titulado quijotescamente "Juventud contra molinos de viento", aparecido inicialmente en 1925: "Se nos reconviene luego por falta de nacionalismo, sin profundizar el alcance del problema. ¿Por qué tampoco lo hubo en las generaciones del pasado? ¿Puede producirlo un país sin unidad racial? $\mathrm{Y}$ aún ¿el arte nacionalista es superior al simplemente humano?"22.

\section{La familia literaria de Francisco Tario}

Ignacio Trejo Fuentes incluye a este narrador entre aquellos autores mexicanos que "trabajaban historias estrambóticas, exageradas y por eso desconcertantes para los lectores de materiales ortodoxos" ${ }^{\text {"23 }}$, ortodoxia que sería dada por la adscripción a la mimesis realista ${ }^{24}$. Aunque los detalles visibles de su vida no lo delatan como escritor maldito en el plano biográfico, ha sido durante mucho tiempo una de las figuras emblemáticas de la paratopía literaria en

${ }^{21}$ José GOROSTIZA, "Hacia una literatura mediocre”, en: Poesía y Prosa, México, Siglo XXI, 2007, 289-291.

22 Ibidem 251.

${ }^{23}$ Ignacio TREJO FUENTES, "Óscar de la Borbolla: La vida de un muerto", Siempre!, asequible en: http://www.accessmylibrary.com/coms2/summary_0286-32200321_ITM, fecha de consulta: 3 de abril de 2007.

${ }^{24}$ En la narrativa hispanoamericana de las primeras décadas del XX "el postulado de la mimesis en cuanto obligación ontológica, epistemológica y ética de la ficción para con la realidad extratextual -la realidad precede a la ficción y configura su meta y su punto de orientación - representa el trasfondo común todavía incuestionado, por lo menos a primera y segunda vista" (Katharina NIEMEYER, Subway de los sueños: alucinamiento, libro abierto. La novela vanguardista hispanoamericana, Madrid / Frankfurt, Iberoamericana / Vervuert, 2004, 58). 
México, tanto por la temática abordada en sus libros como por su propia desubicación dentro de ese marasmo de autores “"condenados' a una temática nacional o popular" que deben "desarrollar, defender, ilustrar, aunque sea criticándolas, las aventuras, historias y controversias nacionales" ${ }^{\prime 25}$. Así Porfirio Romo, director de la editorial Lectorum, señaló que "Tario no corresponde a la época en que escribe, por eso fue incomprendido en su momento. Hizo mucha abstracción cuando no se estilaba, cuando el realismo tenía bases muy fuertes" ${ }^{26}$. Y a ojos de las "buenas conciencias" literarias, cometió -entre otros- el pecado de indagar "en uno de los terrenos menos frecuentados en México durante los cuarenta: el miedo" 27 .

Una piedra de toque de su recuperación puede cifrarse en la publicación de la antología Paisajes del limbo, donde Mario González Suárez lo sitúa entre los que denomina "narradores del limbo", junto a Guadalupe Dueñas, Salvador Elizondo, Ricardo Elizondo Elizondo, Pedro F. Miret, Arqueles Vela, Efrén Hernández $^{28}$, Jesús Gardea, Juan Vicente Melo o Daniel Sada. La nómina de González Suárez nos permite introducir el concepto de familia literaria tal como lo entiende Pascale Casanova ${ }^{29}$, extrapolando la figura de Tario al ámbito más amplio de América Latina, algo que ya hizo Ángel Rama en el caso de un autor que precede en algunos años a Tario pero que comparte con él una posición muy similar: el venezolano Julio Garmendia, quien, con la formulación del programa antirrealista contenido en su texto "El cuento ficticio", "se sitúa implícitamente en la tradición de los cuentistas [...] que viniendo del simbolismo escriben le conte fantastique ${ }^{\text {"30 }}$. Ángel Rama emparenta literariamente a

\footnotetext{
25 Pascale CASANOVA, La República mundial de las Letras, Barcelona, Anagrama, 2001, 251.

${ }^{26}$ Citado en: Patricia CORDERO, "Reconocen fantasía de Francisco Tario", El Norte, asequible en http://www.accessmylibrary.com/coms2/summary_0286-903771_ITM, fecha de consulta: 24 de febrero de 2006.

${ }_{27}$ Guillermo SAMPERIO, “Tario: el corrosivo eterno", en: El club de los independientes, México, Lectorum, 2005, 124-126.

${ }^{28}$ Una vez que nos adentramos en este limbo, las referencias se retroalimentan; para Héctor Perea, Efrén Hernández era un "narrador cercano a Contemporáneos que tendría poca pero intensa descendencia en cuentistas raros como Francisco Tario y el catalán Pedro F. Miret”, y también un antecedente de "una generación de escritores interesados en los temas urbanos y los ambientes cultistas": la organizada en torno a la Casa del Lago (Héctor PEREA, Los respectivos alientos, UNAM, 2006, 194).

${ }^{29}$ Ella señala la conveniencia de "constituir 'familias' literarias, conjuntos de casos que, aunque a veces están muy alejados en el espacio y en el tiempo, están unidos por un 'parecido de familia"' (CASANOVA, op. cit., 234).

30 Anamaría de RODRÍGUEZ, "Sobre 'El cuento ficticio' y sus alrededores", en: Juan Carlos SANTAELLA (ed.), Julio Garmendia ante la crítica, Caracas, Monte Ávila, 1980, 110.
} 
este narrador con "otros solitarios de distintos puntos, desconocidos entre sí" 31 , que constituirían "La familia latinoamericana de Julio Garmendia", cohesionada por una labor que obedecería a la comunión de intereses artísticos comunes y no a un flujo de influencias recíprocas. De este modo, Garmendia sería

el representante venezolano de una gran familia formada por otros jóvenes solitarios y esperanzados en distintos puntos del continente, quienes sólo tardíamente se conocieron entre sí y trabajaron mucho tiempo con la sensación de hostilidad o incomprensión de sus medios intelectuales. A ellos se vincularon algunos mayores, incluso algunos reservistas que esperaron a que aparecieran para optar por esa nueva familia (Julio Torri en México, Graça Aranha en Brasil, Macedonio Fernández en Argentina) ${ }^{32}$.

En este sentido, las siguientes apreciaciones de Anamaría de Rodríguez acerca de los textos de Garmendia y su "familia" o cofradía literaria son aplicables en buena medida a la carrera literaria de Francisco Tario y la suerte de que ha gozado:

Estos textos que hoy se nos hace perentorio poner en relación entre sí, y que aparecen claramente oponiéndose a la estética dominante cuando surgieron, sufrieron un desconocimiento que no dependía estrictamente de la ineficacia de la crítica y del público para entender su alcance subversivo. Si en su momento fueron ignorados, o en el mejor de los casos causaron desconcierto, fue porque alteraban las categorías de la práctica literaria que en la época tendía a convertirse en canon dominante con mecanismos que de ninguna manera coincidían con ese canon. Ahora bien en el momento actual nuestra situación como lectores está inversamente calificada: podemos leer estos textos que configuran una producción literaria de las características precursoras desde la perspectiva de un post-conocimiento: el del desarrollo que siguió la literatura hispanoamericana y en base al cual podemos intentar la determinación de su lugar dentro del proceso de las tradiciones del relato en Latinoamérica ${ }^{33}$.

Tario, como los demás escritores citados, produjo obras relegadas en su momento, que permanecerían en un estado de latencia hasta que la forja de un

31 Ángel RAMA, "La familia latinoamericana de Julio Garmendia", en: Ensayos sobre literatura venezolana Caracas, Monte Ávila, 1991, 77. El término "solitario" empleado por Rama no carece de relieve, pues según algunas hipótesis la génesis del seudónimo Francisco Tario se hallaría en este, y de ello se hace eco González Suárez en el título de su prólogo a la compilación de los cuentos completos del autor publicada en 2004 por Lectorum ("En compañía de un solitario").

${ }^{32}$ Ibidem, 77-78. El énfasis es mío.

33 Anamaría de RODRÍGUEZ, art. cit., pp. 106-107. El énfasis es mío. 
nuevo horizonte de expectativas proclive a una recepción favorable ha permitido en años recientes su recuperación y aceptación. Bourdieu advierte que

La lisibilité d'une oeuvre d'art est fonction, pour une société donnée, de l'écart entre le code qu'exigé objectivement l'œuvre considérée et le code artistique disponible pour un individu particulier, de l'écart entre le code, plus ou moins complexe et raffiné, qu'exigé l'œuvre et la compétence individuelle, définie par le degré auquel le code social, lui-même plus ou moine adéquat, est maitrisé ${ }^{34}$.

Por ello, una obra de arte ofrecería sentido e interés para el receptor que esté en posesión de la competencia cultural necesaria para decodificarla. La adquisición de dicha competencia cultural y de hábitos necesarios para llevar a cabo la decodificación de esos textos por parte de las generaciones posteriores haría posible su revalorización.

Hugo J. Verani profundiza en este fenómeno, refiriéndose al campo literario uruguayo -y dentro de él, más concretamente, a Felisberto Hernández. Aporta los mismos nombres, así como otros nuevos, y los presenta como protagonistas de un fenómeno que rebasa las fronteras nacionales:

Hacia mediados de la segunda década del siglo XX surge en el Uruguay, como en el resto de Hispanoamérica, una narrativa que presenta contornos imprecisos e inquietantes, un tipo de ficción que contrasta radicalmente con el realismo testimonial de las corrientes mayoritarias, la narrativa nativista, cuya tónica dominante era la representación literaria de valores autóctonos bajo esquemas racionales y lógicos. Cuando aparece una literatura insurgente, que responde a impulsos de ruptura, se la recibe con indiferencia o se la margina. Por estas razones, los escritores que interiorizan la perspectiva narrativa y conciben la literatura como un acto imaginativo (Roberto Arlt, Macedonio Fernández, Juan Emar, Martín Adán, Julio Garmendia, etc.) fueron relegados durante décadas, para revalorizárseles tras el auge de la narrativa de los sesenta, al promoverse el rescate de quienes abren el camino con obras de ficción infinitamente más estimulantes que la de tantos epígonos de la tradición naturalista ${ }^{35}$.

Esta familia literaria se caracterizaría por unas opciones estéticas heterodoxas y por su alejamiento de las tradiciones mayoritariamente vigentes en la primera

\footnotetext{
${ }^{34}$ Pierre BOURDIEU, "Sociologie de la perception esthétique", en: Les Sciences bumaines et l'oewrre d'art, Bruxelles, La Conaissance, 1969, 169.

35 Hugo J. VERANI: "Felisberto Hernández: la inquietante extrañeza de lo cotidiano", en: Anales de literatura hispanoamericana 16, 1987, 127. El énfasis es mío.
} 
mitad del XX, "organizadas por un sistema literario que lo acostumbra a las analogías y pretendidas paridades entre el universo de ficción y la realidad de la literatura (inicios de la tradición regionalista-rural, que recibe y adapta la tradición naturalista, etc.)" ${ }^{\prime 36}$, con el consiguiente apartamiento del horizonte de expectativas generado por ellas. Verani vuelve a tratar la misma problemática suscitada por las obras de los narradores de esa época afines a las técnicas vanguardistas y a temas que poco tenían que ver con los parámetros exigidos:

Como toda narrativa que quebrantaba normas consolidadas fue marginada por el apogeo del regionalismo mundonovista, que produjo la llamada novela de la tierra, expresión nacional de incuestionable arraigo popular. Sin embargo, la presencia de una narrativa contestataria fue más abundante y considerable de lo que suelen reconocer las historias de la literatura hispanoamericana. No se trata de casos esporádicos, sino de un grupo de escritores que parten de una actitud de ruptura, impulsados por una imaginación sin restricciones, que no adquiere aceptación hasta mediados de los sesenta ${ }^{37}$.

Serían obras integrantes de una corriente que podríamos calificar de subterránea, no precisamente porque fuese exigua, sino por la desatención que recibió. Nelson Osorio Tejeda señala algunas de sus características principales y la incidencia de estas en su recepción:

El suelto desenfado y a veces hasta la displicencia con que estas obras se situaban ante los "valores consagrados", la deliberada desacralización que implicaban del lenguaje dominical y "poético" que entonces definía "lo literario", preferencia por personajes marginados del sistema, el predominio de la narración personal, la interiorización de la perspectiva narrativa que en todas asoma, ese "vanguardismo", en fin, que las caracterizaba, hicieron que se atravesaran en la garganta del encorbatado gusto (que, por supuesto, era el "buen gusto") que predominaba en los lectores y sobre todo en los críticos de ese momento ${ }^{38}$.

La metáfora que utiliza Osorio sobre la dificultosa "deglución" que la obra de estos autores planteaba a crítica y público lector nos retrotrae a los principios de estética de la recepción ya mencionados. Pese a guardar un aire de familia inconfundible con estos autores, la reivindicación de Francisco Tario ha sido

36 Anamaría de RODRÍGUEZ, art. cit., pp. 110-111. El énfasis es mío.

${ }^{37}$ Hugo J. VERANI, "La casa de cartón de Martín Adán y el relato vanguardista hispanoamericano", en: Antonio VILANOVA (ed.), Actas del X Congreso de la Asociación Internacional de Hispanistas (vol. IV), Barcelona, PPU, 1989, 1077.

${ }^{38}$ Nelson OSORIO T., "La tienda de muñecos de Julio Garmendia en la narrativa de la vanguardia hispanoamericana", en: Julio Garmendia ante la crítica, op. cit., 152. El énfasis es mío. 
más tardía y no ha comenzado a hacerse patente hasta comienzos del presente siglo. La ausencia de su nombre en estas nóminas es sintomática de que incluso dentro de la marginalidad cabe una gradación de intensidad, y Tario la detentaría en mayor medida que los mencionados Felisberto Hernández (quien fuese abiertamente reivindicado por Cortázar y Calvino), Pablo Palacio, Julio Garmendia o Macedonio Fernández (prestigiado por los elogios de Borges). Por ello se situaría, en función de esos parámetros, en una zona de invisibilidad literaria más próxima a Juan Emar o Martín Adán. Alejandro Toledo habla de la posición de Tario dentro del campo literario mexicano y de la movilidad que ha hecho posible su reconfiguración, en buena medida condicionada por la mirada del receptor:

Los mapas literarios no son piezas inmóviles: van cambiando según el que las mira. Tario no se esforzó por aparecer en la fotografía junto a sus contemporáneos. Si está ahí es como fantasma, es decir, como un ser invisible. Está pero no se ve. Otros están pero ya no los miramos, ya no los leemos, se han invisibilizado o tienden a ello. La imagen se deslava. Y el que observa cambió en espíritu, o se volvió él mismo un espíritu ${ }^{39}$.

Asimismo, esa marginalidad o la ausencia de ella vienen determinadas por las credenciales otorgadas desde los organismos sancionadores y dadores de prestigio no necesariamente en base a criterios de calidad literaria, como bien apunta el crítico en una reciente entrevista, a colación de algunos de los autores que nos ocupan:

Efrén Hernández, Felisberto Hernández, Francisco Tario, Antonio Porchia... escritores raros — como Darío y tú los nombran—, marginales, excéntricos... ¿por qué raros, por qué marginales?

El escritor alemán Walter Muschg, en su Historia trágica de la literatura, habla de que en las primeras décadas del siglo XX hay un proceso que llama de "americanización" de la literatura. Al escritor se le da un poder social, él mismo anda en busca de la fama y del premio; el aspecto comercial comienza a serle muy importante. Las figuras excéntricas, marginales, están al margen de esto, justamente. Por eso ocupan ese lugar en apariencia secundario, porque no aceptan las reglas del mercado. Quizá algo de eso surgió con Rubén Darío al publicarse su libro Los raros, a finales del siglo XIX y cuyas manifestaciones se continúan en el siglo XX. Uno cree que los escritores buenos son los que reciben los premios, que tienen un nombre

\footnotetext{
${ }^{39}$ Citado en José LARA, "Francisco Tario, el raro o cronopio de la literatura mexicana", asequible en http://www.conaculta.gob.mx/saladeprensa/index.php?indice=4\&fecha=2005-04-14, fecha de consulta: 10 de junio de 2010 .
} 
porque han logrado ubicarse en los panoramas literarios. Pero resulta que no, que los raros, los subterráneos, son los que marcan de pronto un camino, una raíz, y sobre todo son los que perduran. Por lo menos esa ha sido mi experiencia ${ }^{40}$.

Por ello, matiza "que la marginalidad sólo es aparente. Es un fenómeno social. La señalan, en negativo, quienes están atentos a los escalafones"

Toledo, acertadamente, se había servido ya con anterioridad de la distinción cortazariana entre famas y cronopios para ilustrar las dinámicas de la consagración y la marginalidad operantes en el seno de la movediza institución literaria:

Un fama es el que apuesta por el presente (como "inmortal del momento", según la fórmula acuñada por José de la Colina), y un cronopio es el que vive con sus propios relojes: a éste le da igual aparecer o no en el suplemento del domingo pero estará en él, probablemente, dentro de cincuenta años, aunque tampoco le obsesiona ese tipo de "estar". Los famas andan a la caza del reconocimiento, y los cronopios van por sus caminos individuales. A los famas les gusta mostrarse como serios escritores profesionales (dar entrevistas y conferencias, aparecer en la televisión como sabios opinadores, organizar tumultuosas presentaciones de libros y conseguir becas y premios), mientras que los cronopios se ejercitan en el arte de la informalidad. Los famas creen que por ser conocidos serán leídos, y de esa manera justifican su obsesión por la foto o el titular en el diario; los cronopios entienden que sólo por sus obras los conoceréis. El fama brilla en sociedad; al cronopio se le etiqueta (en homenaje a Rubén Darío) como "raro". Las siguientes líneas de un cuento cortazariano ("Simulacros") suelen funcionar como ars poetica de lo marginal (extravagante, estrafalario, excéntrico o desencuadernado y una infinidad de sinónimos al gusto de cada quien): "Somos una familia rara. En este país donde las cosas se hacen por obligación o fanfarronería, nos gustan las ocupaciones libres, las tareas porque sí, los simulacros que no sirven para nada" ${ }^{42}$.

\footnotetext{
${ }^{40}$ Lucía SEDANO, "Efrén: el mínimo y dulce. Conversación con Alejandro Toledo", Correo. Diario del estado de Guanajuato, asequible en: http://www.correo-gto.com.mx/notas.asp?id=26567, fecha de consulta: 21 de junio de 2010.

${ }^{41}$ Idem.

42 Alejandro TOLEDO, "Prólogo" a: El hilo del minotauro. Cuentistas mexicanos inclasificables, México, FCE, 2006, 12-13. Puntualiza que estas condiciones no implican la carencia o posesión de maestría literaria, "pues hay famas con talento y cronopios de utilería" (ibidem, 14-15).
} 


\section{Conclusiones}

Alí Chumacero consideraba que el espíritu nacional mexicano todavía se hallaba en proceso de formación, que no se encontraba plenamente decantado, y de ahí los tanteos advertidos en esa literatura nacional. Quizá por ello México se constituiría como ejemplo paradigmático de que en las naciones jóvenes el papel exigido al escritor conlleva su servidumbre a la irradiación del polo político, una clara muestra de lo que Pascale Casanova describe como una "verdadera hegemonía del 'realismo' en todas sus formas, avatares y denominaciones neonaturalista, pintoresco, proletario, socialista...-, en todos los espacios literarios

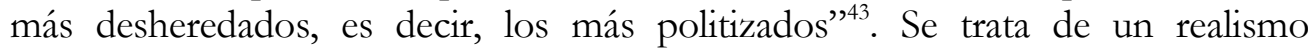
practicado en nombre del compromiso político (compromiso que crea una dependencia estructural de las prácticas literarias con respecto a las instituciones políticas) y que "es, en realidad, un nacionalismo literario ocultado como tal: un realismo nacional" 44 de cuyo programa quedarían fuera los autores de los que me he ocupado. Mario González Suárez ha señalado que en un tramo importante del siglo pasado "la urgencia de la edificación de un estado impidió que se le prestara atención a una literatura que no hablaba de México" ${ }^{45}$, y de este modo se generó lo que Noemí Ulla denomina "la represión de lo imaginario", que sería "una de las modalidades de la cultura que con mayor frecuencia y fuerza someten a la sociedad" ${ }^{46}$. Esa supeditación se prolongaría en décadas posteriores. Así, en los cincuenta, José Luis González consideraba la literatura fantástica como "literatura de avestruz" ". Y a Carlos Fuentes se le reprochó, a raíz de su primer libro de cuentos Los días enmascarados, tener como referente "la decrépita literatura inglesa" y hacer "literatura evasiva y, por tanto, nada americana" $a^{48}$. El propio Fuentes señala que la narrativa mexicana de la década de los 50 debía responder a "tres exigencias simplistas, tres dicotomías innecesarias que, no obstante, se habían erigido en espectáculo dogmático contra la potencialidad misma de la novela: 1. Realismo

\footnotetext{
${ }^{43}$ CASANOVA, op. cit., p. 259.

${ }^{44}$ Ibidem, 261.

${ }^{45}$ Citado en: Patricia CORDERO, art. cit.

${ }^{46}$ Noemí ULLA, "La fantasía en cuentos de Silvina Ocampo y su relación con otros textos hispanoamericanos", en: Enriqueta MORILLAS VENTURA (ed.), El relato fantástico en España e Hispanoamérica, Madrid, Siruela / Sociedad Estatal Quinto Centenario, 1991, 289. Ulla atiende concretamente al ámbito rioplatense, donde la desatención que la corriente fantástica sufrió entre fines de los 50 y de los 70 apunta un desdén por la imaginación que "respondió al sojuzgamiento artístico que proponía una estética limitada a representar la realidad social de América Latina" (idem) y que sometía a los autores a aquello que Kazimierz Brandys llamara el "deber patriótico" del escritor.

${ }^{47}$ José Luis GONZÁLEZ, "Cuatro cuestiones”, en: México en la cultura, no 336, 3.

48 Alfredo HURTADO, "Los Presentes”, en: Estaciones 1, n 3, 396, el énfasis es mío.
} 
contra fantasía y aun contra imaginación. 2. Nacionalismo contra cosmopolitismo. 3. Compromiso contra formalismo, artepurismo y otras formas de irresponsabilidad literaria"49. Estas dicotomías listadas por Fuentes pueden sintetizarse en una bipolaridad abarcadora esencial: la que ha enfrentado regionalismo o localismo a cosmopolitismo, extrapolable a otras naciones hispanoamericanas y que, según Octavio Paz constituyese para sus literaturas "un rasgo en común: la pugna, más ideológica que literaria, entre las tendencias cosmopolitas y las nativistas, el europeísmo y el americanismo" 50 . Todo ello se inscribe en una amplia y prolongada polémica polarizada en esos conceptos enfrentados, en la cual se vieron involucrados autores que con la virulencia de sus vuelos imaginativos desafiaron a una literatura tan atada a las contingencias del medio social y político.

No han faltado, sin embargo, posturas conciliadoras ante esta polarización, como la sostenida por Luis Leal, quien abogó por una actitud no excluyente entre dos tendencias, para él complementarias, en el desarrollo del cuento hispanoamericano. Dichas vertientes serían:

la social y la esteticista. La primera tiene por finalidad captar la realidad americana y darle un significado social; la segunda se conforma con crear una obra de arte, ya sea con materiales nativos o exóticos. Ambas tendencias son manifestaciones genuinas de la literatura hispanoamericana; entre las dos -que se complementan- nos dan una visión completa de la realidad americana, que es tanto social -por lo que tiene de ambiental, de histórico- como artística -por lo que tiene de universal ${ }^{51}$.

Sin embargo, la posición adoptada por él no ha sido la que más predicamento ha hallado entre la intelligentsia literaria hispanoamericana. Salvador Elizondo, en un escrito bautizado significativamente "Desde Ningunia", denunció su propio ostracismo literario, que podría considerarse equivalente al de los autores abordados y otros escritores mexicanos precedentes y coetáneos:

En la tumultuosa corriente del río revuelto de la dizque crítica literaria, si así se puede llamar a las reseñas que aparecen en las revistas oficiales, he visto pasar flotando los cadáveres hinchados de mis amigos y el mío propio bogando a tumbos hacia la disolución y el olvido por obra de los concienzudos críticos que sólo abarcan lo necesario para poder aniquilar el resto de la manera que mejor convenga a sus intereses inmediatos y

${ }^{49}$ Carlos FUENTES, Geografía de la novela, Madrid, Alfaguara, 1993, 17.

50 Octavio PAZ, "La búsqueda del presente", en: Convergencias: ensayos en arte y literatura, Barcelona, Seix Barral, 1991, 9.

${ }^{51}$ Luis LEAL, Historia del cuento hispanoamericano, México, Ediciones del Andrea, 1971, 5. 
salvaguardando la literatura mexicana actual del oprobio, no solamente de nuestra obra, sino hasta de nuestros nombres ${ }^{52}$.

No obstante, esa "Ningunia" evocada por Elizondo ha funcionado a ojos de un número creciente de lectores y críticos en los últimos años como un limbo productivo donde han trabajado autores que han trazado una faz insoslayable para comprender la literatura hispanoamericana desde una perspectiva abarcadora.

${ }^{52}$ Salvador ELIZONDO, “Desde Ningunia”, en: Estanquillo, México, FCE, 2001, 119. 